crudely measured by the volume of successful research grant applications, should qualify for a bonus.

Breaking with tradition, the University Grants Committee should also make explicit the basis on which its allocations of funds are made, so that universities know how most successfully to compete for what funds there are. And something should be done to clarify, simplify and ideally cheapen the present cost to public funds of supporting students in universities. One of the causes of the government's discontent, and the immediate cause of the restriction on student numbers now announced, is the cost of paying student fees and maintenance grants, using local authorities as paying agents. These arrangements, dating back to the days when students were considered to be the salt of the earth, are certainly not the most economical ways of helping to encourage the spread of university education. The anomalies which they include are often inequitable as between one student and another. One of their consequences is that British universities are chronically short of student accommodation. The arrangements should be re-examined, whatever noise the National Union of Students makes.

But why should the universities take the initiative in helping the government to save money, when the government has been so beastly? That is a hollow argument. The objective is not economy but independence. For all its faults, the British university system is a remarkable and valuable institution. The most immediate danger is that it will be so demoralized by the three painful years ahead that its capacity for self-renewal will be permanently impaired, as will be its capacity to persuade those who must support it that even its present role, even in present circumstances, is indispensable. The most cruel irony is that the British university system has been so mindlessly attacked when it is more than ever apparent that Britain lacks many of the skills that the universities could cultivate.

\section{Clinch River runs again}

During President Carter's tenure at the White House, the fast reactor site at Clinch River in Tennessee seemed destined to become a special kind of white elephant - a collection of unused equipment surrounding a half-begun concrete structure that would for all time be a monument to the fancied folly of the $1960 \mathrm{~s}$ that it would be possible economically to win power from a nuclear reactor making more fuel than it consumed. Now, the prospects are changing. Against expectations and the recent voting record of the key committees in the House of Representatives, Congress appears to be ready to see work at the reactor site begin again (see Nature, 16 July). President Reagan, having spoken fondly of Clinch River during his election, dutifully included in his budget in March a request to Congress for funds to start building again at Clinch River. But the issue has never seemed important enough to the Administration to justify the risks of a serious fight. In the end, local interests in Congress have given the Administration what it was asking for without blood being spilled. The embarrassment, for President Reagan, is that he must now ask the Department of Energy to brush up its policies in other parts of the domestic nuclear energy programme.

Although the completion of Clinch River has for some time seemed to be an acid test of the willingness of the United States to commit itself to fast reactor technology, appearances are false. The Clinch River design is more than a decade old; much has since been learned, especially in France, about the design and operation of fast reactors. The escalation of the cost of the project, by a factor of three or thereabouts, is a measure not so much of the optimism of its original designers as of the need for changes of design after construction had begun. The enforced four-year delay will not have helped. Clinch River may yet be a white elephant of a different kind, a representation of an earlier technology. Even so, it will provide some practical experience of the operation of nuclear reactors cooled by liquid metal (sodium). And it will be another spur to the continuing wrangle in the United States about the rights and wrongs of nuclear power.
Technically, Clinch River is a demonstration plant, intended to demonstrate to utilities and their customers that electricity can be produced safely from fast reactors and that, in due course, fast reactors could be built economically. The demonstration would have been more helpful if the design had been less out of date. But in the assessment the utilities will eventually have to make, one crucial piece of information will be missing. The economic case for breeder reactors of any kind (which need not be fast reactors) is that they can use plutonium as fuel. When President Carter took fright at the prospect of the "plutonium economy", the extraction of plutonium from spent fuel rods taken from existing reactors was suspended. The Administration's new and sensible policy on the proliferation of nuclear weapons (see page 281) will help to liberate the Department of Energy from the traditions of the recent past, but there is a lot to be done before the economics of the plutonium fuel cycle can be tested. Completing Clinch River will, however, be a nonsense if that is not quickly done.

The wider implications of Clinch River in the nuclear debate are not at this stage easy to foresee. The most serious argument in recent years against breeder reactors has been economic; the price of uranium has risen so much less quickly than that of fossil fuels, and the cost of electricity is so much less dependent on the cost of fuel in nuclear reactors than in fossil power plants, that the potential advantages of breeder reactors (fuel at no cost at all) are not worth striving for. So why not put the huge cost of development into more imaginative exploits? The argument is respectable, and deserves attention. Its flaw is its assumption that the relative prices of uranium and fossil fuel will remain what they are at present for two or three decades ahead. The snag, of course, is that the present price of uranium (about $\$ 50$ for a pound of uranium oxide) reflects the decline in the rate at which utilities have been ordering conventional nuclear plants in the past few years. If, as memories of Three Mile Island fade, and the lessons of that accident are properly learned, the utilities turn again to nuclear power as a source of electricity, the price of uranium would shoot up. Is it not, in such circumstances, prudent that there should be data about the operation of some breeder reactor that would allow sensible decisions to be made?

Less cogent arguments have been made by those who say that fast reactors are inherently less safe even than conventional nuclear plants. Anxiety of this kind stems from the observation that breeder reactors contain substantial amounts of fissile material, and that the neutrons involved in the nuclear chain reaction are fast and therefore, on the face of things, likely to complicate the control of fluctuations of reactor output. Neither argument is as persuasive as it seems, however. Weapons designers are always saying that their most serious problem is that of arranging that fissile material can be coaxed into some configuration that will explode, so that the risk that such a configuration will turn up by accident in a breeder core is likely to be small; certainly the risky configurations can with ingenuity be identified in advance; and steps can be taken to avoid them or to prevent the damage they would do. And anxiety about neutron speed should be offset by the relatively low thermal inertia of fuel elements in fast reactors and the high thermal capacity of the molten sodium. None of this suggests that there are no risks in completing Clinch River but merely that theoretical safety studies have probably now gone as far as they can.

The third foundation of the case against Clinch River, of which much will be heard in the weeks ahead, is that all nuclear reactors are an abomination and that fast breeders are a particular abomination because one of their products is plutonium, sometimes described as the "most poisonous substance on earth" and sometimes feared because it might be used for making weapons clandestinely. The arguments presuppose that neither the safety of nuclear plants nor the security of the material they produce can be held within reasonable limits. Yet even the colourful experience of Three Mile Island, essentially a demonstration that it is possible so seriously to damage a nuclear plant that it is virtually useless without scattering dangerous doses of radioactivity in the neighbourhood, cannot be used unambiguously to support the case against Clinch River and what might follow. 